Revue de l'Institut des langues et cultures

d'Europe, Amérique, Afrique, Asie et Australie

$25 \mid 2016$

De la bibliothèque intérieure à la bibliothèque collective : livres et lectures en Espagne (XVIe-XXI siècles)

\title{
La Editorial Séneca (México, 1940-1948) o la biblioteca interior del exilio republicano español
}

The Publishing House Séneca or the "Inner Library" of the Spanish Republican Exile in Mexico (1936-1946)

La maison d'édition Séneca ou la «bibliothèque intérieure » de l'exil républicain español au Mexique (1939-1946)

\section{Salomé Foehn}

\section{OpenEdition}

Journals

\section{Edición electrónica}

URL: http://journals.openedition.org/ilcea/3720

DOI: $10.4000 /$ ilcea.3720

ISSN: 2101-0609

Editor

UGA Éditions/Université Grenoble Alpes

Edición impresa

ISBN: 978-2-84310-322-3

ISSN: 1639-6073

Referencia electrónica

Salomé Foehn, «La Editorial Séneca (México, 1940-1948) o la biblioteca interior del exilio republicano español », ILCEA [En línea], 25 | 2016, Publicado el 31 enero 2016, consultado el 21 abril 2019. URL http://journals.openedition.org/ilcea/3720 ; DOI : 10.4000/ilcea.3720

Este documento fue generado automáticamente el 21 abril 2019.

(C) ILCEA 


\title{
La Editorial Séneca (México, 1940-1948) o la biblioteca interior del exilio republicano español
}

\author{
The Publishing House Séneca or the "Inner Library" of the Spanish Republican \\ Exile in Mexico (1936-1946) \\ La maison d'édition Séneca ou la «bibliothèque intérieure " de l'exil républicain \\ español au Mexique (1939-1946)
}

\section{Salomé Foehn}

«Un livre est un objet qui vient de loin. Il témoigne d'un monde non entièrement perdu.» Chris YounÈs y Benoît GOETZ

Al final de la guerra civil española, aún en París, la Junta de Cultura Española (JCE), que en asuntos culturales representaba al gobierno republicano español en el exilio, encargó a José Bergamín que creara, en México, una editorial que promocionara la visión de la España progresista y democrática, cuyos valores radicaban, como lo mostraré, en el «humanismo español» (Foehn, 2014); más precisamente en su vertiente populista. La Editorial Séneca ${ }^{1}$ fue inaugurada en 1940 en la capital mexicana. En sus diez años de existencia ${ }^{2}$, publicó parte del «Plan general de publicaciones» redactado por el mismo Bergamín (Dennis, 2005: 30). No pretendo aquí ofrecer una historia revisada de la Editorial Séneca, sino exponer en último término cómo Séneca fue, pese a su fracaso, un lugar propicio para que los expertos más idóneos ${ }^{3}$ entablaran un diálogo en torno a filosofía y poesía. Tan sólo apuntaré que Nigel Dennis me señaló, años atrás, que Bergamín expuso en una carta a Negrín a principios de 1939 las razones para crear la JCE, que nunca fue retomada por los documentos oficiales posteriores, ni, por consiguiente, por la historiografía contemporánea ${ }^{4}$ :

Cuando estuve en San Sebastián hace poco, conocí a un hombre cuyo nombre me era vagamente familiar (había editado un libro de Luisa Carnés para la Biblioteca del Exilio ${ }^{5}$. Tomamos un café un día y el tema de la Junta de Cultura se presentó.

Dijo que había consultado los archivos del Ministerio de Asuntos Exteriores años 
atrás y encontrado un documento relacionado con la creación de la Junta de Cultura. Pedí una copia y me la mandó. Resultó ser la propuesta que Bergamín sometió a Juan Negrín a principios de 1939 para la fundación de la Junta, exponiendo todas las razones (no mencionadas en los documentos oficiales posteriores sobre el asunto) por las que era necesaria la Junta en aquella época. En otras palabras, un documento inapreciable, histórico, directamente vinculado a un asunto que me interesa sumamente.

2 A mi conocer, no existe aún una monografía sobre la JCE, para la cual haría falta una investigación archivística en ambos lados del Atlántico. Para este trabajo he tenido que consultar esencialmente un fondo bibliográfico esparcido, dedicado sobre todo al estudio de España Peregrina y de Séneca, o, también, a Bergamín durante su exilio mexicano. En la primera parte de este artículo insistiré en el papel clave que desempeñó Bergamín como Director literario, artístico y técnico de Séneca, basándome en los estudios preliminares de Nigel Dennis a El pasajero. Peregrino español en América y Prólogos epilogales, de Bergamín.

Usaré el concepto de Pierre Bayard de «libro-fantasma» como «objet insaisissable et mouvant que nous faisons surgir par oral ou par écrit, quand nous parlons d'un livre» (2007: 140) aplicándolo al exilio republicano español. Las circunstancias del exilio se repercuten hoy en día sobre la edición de la obra posterior a 1939 de numerosos autores -entre ellos Bergamín y García Bacca-, de manera que muchas veces se hace necesario consultar los textos originales, publicados en Hispanoamérica y no pocas veces inasequibles en Europa. Se ha remediado en parte a ese estado en contados casos de autores cuyas Obras completas han sido publicadas (como fue el caso, entre los filósofos, de José Gaos y, más recientemente, de María Zambrano). Desde el punto de vista del lector y del investigador contemporáneos, el «libro-fantasma» del que habla Pierre Bayard también envuelve las ediciones agotadas o, en el mejor de los casos, parcialmente reeditadas en España. En este artículo ilustraré esa precariedad editorial debida a las circunstancias del exilio mediante el ejemplo de Hölderling [sic] y la esencia de la poesía, de Martin Heidegger, en la traducción al castellano de Juan David García Bacca. En la época en que se iniciaba el exilio republicano, se hizo pronto sentir la escasez de material bibliográfico. Por lo cual cabe preguntarse ¿cuántos libros se convirtieron en «libros-fantasma» al iniciarse el exilio? El mismo Bergamín, según nos cuenta Gonzalo Santonja, estaba de viaje a Estados Unidos como delegado oficial de la Segunda República, cuando se encontró exiliado; las tropas franquistas saquearon su casa en Madrid (Santonja, 1997: 18). En Confesiones, Juan David García Bacca recuerda que unos amigos le trajeron los libros que de su biblioteca de la Universidad de Barcelona pudieron rescatar, cuando él estaba a punto de marcharse a Quito (2000: 68-69).

Huelga decir que Pierre Bayard escribió Comment parler des livres que l'on n'a pas lus sin tener en mente el exilio republicano español de 1939, ni, tampoco, la labor cultural y editorial que desempeñaron los intelectuales del exilio republicano español de 1939 en Hispanoamérica durante cuarenta años. En un admirable esfuerzo colectivo, los exiliados tuvieron que inventar de nuevo aquellos tesoros de bibliotecas destruidas por los huestes franquistas $-\mathrm{y}$ no siempre con éxito. Cuando sobran los libros, los lectores pueden convertirse en «no lectores», en hombres de cultura que, como Pierre Bayard, hablan de libros que no han leído; en las primeras décadas del destierro, sin embargo, el libro fue, por así decirlo, el terreno en que dialogaban todas las formas de la cultura y del saber universal, al tiempo que se anhelaba preservar el «legado espiritual» de la patria (término entendido en sentido amplio): lo escrito y lo gráfico, lo racional y técnico-académico, la 
teología y la mística, así como la poesía y las artes que constituyen el espíritu y la letra de la «España Peregrina».

5 A partir de las nociones propuestas por Pierre Bayard en el mencionado ensayo, examinaré la dimensión universalista de la «biblioteca interior» (2007: 74) del exilio republicano español en México, con el fin de mostrar cómo, en aquellos años, la Editorial Séneca materializó aquel legado espiritual de España, articulándose material e ideológicamente en torno al hiato creado por el exilio. En primer lugar, adaptaré el marco nocional de Pierre Bayard al primer exilio y a la existencia de Séneca (1939-1949) para luego examinar algunas de las publicaciones de Séneca que mejor ilustran el llamado «humanismo español» en su vertiente popularista que la historiografía suele pasar por alto, imprescindible, en mi opinión, para entender cómo emergió la razón poética como horizonte del exilio republicano español.

\section{Tipología de la biblioteca del exilio}

Incluso antes de recordar que, desde la Antigüedad griega y latina, después de la muerte, no hay condena más grave que el exilio, sería menester insistir en el hecho de que, hoy en día, más de cuarenta años después del retorno de los supervivientes de la guerra y del exilio, sigue siendo difícil conocer y difundir el legado cultural de los intelectuales republicanos en el exilio a nivel europeo, por razones a la vez institucionales y editoriales. Pese a los esfuerzos considerables de los últimos cuarenta años por repatriar lo que constituye a la vez una biblioteca del exilio y una biblioteca de intelectual (Bayard, 2007: 27), el empeño emprendido en la España de la transición, salvo en casos muy contados, no fue prolongado en el resto de Europa.

7 Para analizar esta biblioteca, propongo aquí adaptar al exilio republicano español en México las nociones más relevantes que introduce en su citado ensayo Pierre Bayard, basándose en obras o figuras literarias concretas, relativas a las prácticas del intelectuallector (también, las más veces, autor) y a la constitución del universo inconfundible, a la vez colectivo y personal, que es una biblioteca: el «no lector» ${ }^{6}$, la «biblioteca colectiva / de libros pantalla $»^{7}$ y la «biblioteca interior / de libros interiores $»^{8}$. Todas son variaciones tipológicas de la biblioteca «real», concreta y física (objetiva en el sentido filosófico de la palabra). A partir de esas nociones individuales se pueden elaborar binomios antitéticos: lector / no lector; biblioteca colectiva / biblioteca real; biblioteca interior / biblioteca virtual.

El primer binomio opone el lector al no lector. En la Europa de los años 1920 y 1930, la idea de la cultura como lucha y resistencia contra la barbarie y el fascismo, así como la función del escritor o intelectual como "combatiente de la cultura» se definieron durante el Congreso Internacional de Escritores Antifascistas para la Defensa de la Cultura, de 1935, del que resultó la Asociación Internacional de Escritores para la Defensa de la Cultura o AIDC (Aznar Soler, 2007: 93) y el Segundo Congreso Internacional de Escritores Antifascistas en Defensa de la Cultura, ya en plena guerra civil española (1937), en el que se destacó por varias de sus intervenciones José Bergamín, futuro Director literario y artístico y, asimismo, técnico de la Editorial Séneca. Difícilmente se puede hablar, a escala generacional, de «no lectores»; menos en el caso de Bergamín. Considero que su generación pertenecía, en el exilo, a la categoría de lectores, o, si se prefiere, a la tradición 
europea de «grandes lectores» humanistas, lo que ilustra plenamente su labor editorial posterior al exilio.

El segundo binomio opone la biblioteca colectiva a la biblioteca real. La biblioteca colectiva es la que permite a los republicanos españoles habitar el exilio. Se elaboró a partir del «Plan general de publicaciones» ideado principalmente por Bergamín en contra del programa de des-culturalización de la ya bien instalada dictadura franquista. De ello es ilustrativa la edición de la Obra de Antonio Machado. Según Bayard, la biblioteca colectiva se opone a la biblioteca real y se declina a su vez en «biblioteca interior» y en «biblioteca virtual». Dentro del contexto del exilio republicano español en México, en cambio, se superpone o, incluso, se confunde, con la biblioteca real. El «Plan General de publicaciones» que Bergamín redactó en 1939 es, como bien observa Nigel Dennis, un «plan ideal», que indica lo que pudiera haber sido la empresa de la Editorial Séneca si no se hubiera encontrado en condiciones tan difíciles como lo fueron las del exilio republicano español de 1939. Profundizaré este aspecto en la segunda parte del artículo.

El tercer binomio opone la biblioteca interior a la biblioteca virtual. En rigor, biblioteca interior y biblioteca virtual no se oponen sino que se sitúan en dos órdenes distintos: el personal y el mundano. Ambas, en efecto, dependen de la biblioteca colectiva. La primera tiene una función estructurante y, por lo tanto, es perdurable; la otra, cuya función es social, es un espacio fluctuante situado en el punto de encuentro de las bibliotecas interiores de cada uno de los participantes a la discusión escrita u oral. Se compone de «libros fantasma»: objetos cambiantes que inventamos cuando hablamos por escrito o de viva voz de un libro (real). He sugerido anteriormente que el propósito de la editorial Séneca es estructurar, por así decirlo, la personalidad de la España del exilio, permitirle que no cese de existir en coyunturas tan desfavorables como lo son las del exilio. Ese afán ha sido interpretado -erróneamente en mi opinión- como nacionalismo, si no político, al menos cultural.

\section{El proyecto bibliográfico de la Junta de Cultura Española. La Editorial Séneca o la «biblioteca interior» del exilio}

11 En marzo de 1939, en París, se constituyó la Junta de Cultura Española, dependiente del Servicio de Evacuación de los Refugiados Españoles (SERE), de la que José Bergamín asumió la Presidencia. En mayo Bergamín encabezó la delegación de la Junta invitada a México por el Presidente Lázaro Cárdenas, siempre con la misión de rescatar a los intelectuales (científicos, académicos y artistas) de los campos franceses y de la dispersión inevitable del exilio: con ese fin se creó, con fondos del SERE, la revista España Peregrina cuyo primer número salió en febrero de 1940- y la Editorial Séneca ${ }^{9}$. Numerosos estudios existen tanto sobre la revista (Abellán, 1996; Férriz Roure, 2002; Foehn, 2011; Hidalgo Nácher, 2015) como la editorial (Eisenberg, 1985; Dennis, 1999; Santonja, 1998; Díaz Arciniega, 2014) pero preciso que en ninguno se considera la Editorial Séneca como la biblioteca interior del exilio mientras se constituye, que es la perspectiva que adopto aquí.

Para el aspecto que nos interesa aquí, cabe recordar, con Teresa Férriz Roure, que, entre las actividades que fueron realizadas en México para compensar las carencias del destierro, se creó el proyecto de una Biblioteca colectiva «que sirviera para compensar la 
pérdida de los materiales bibliográficos necesarios para continuar los trabajos emprendidos en España» (2002). Insiste Férriz Roure en el apuro del proyecto:

La urgencia era tanta que difícilmente hallaremos, durante los primeros momentos del destierro, ninguna investigación o escrito exiliado en que no se advierta la precariedad en los materiales de estudio [...]. La misma España Peregrina las ejemplifica, supliéndolas, casi siempre, con citas de memoria, fragmentos de autores o libros recogidos un tanto anárquicamente (en el mejor de los casos), procedentes de las últimas obras leídas por los redactores, nuevas redacciones de lo publicado o escrito con anterioridad, e incluso reimpresiones de artículos ya editados.

El apasionado llamamiento que se hizo desde el primer número de España Peregrina mostraba esa necesidad de conseguir un fondo bibliográfico mínimo [...]. Para justificar esta petición se utilizó el mismo argumento que sustentaba la propia Junta: la necesidad de mantener la unión de los republicanos a partir de la que se convirtió en la gran justificación del exilio: la defensa de la propia cultura (2002).

La creación y la dirección de la Editorial Séneca fue, sin lugar a dudas, la más importante de las actividades culturales emprendidas por Bergamín durante su estancia en México (Dennis, 2005: 27) ${ }^{10}$. Redactó el «Plan general de publicaciones» para la editorial en el verano de 1939, que Nigel Dennis califica de «plan ideal», precisando que se trata «de un esbozo de lo que se hubiera podido hacer si hubiesen sido menos problemáticas las circunstancias del exilio» (Dennis, 2005: 28). Por lo tanto, «no refleja fielmente la labor llevada a cabo por la editorial» (Dennis, 2005: 28). Comenta Gonzalo Santonja que «Séneca nacía sin restricciones programáticas, interesada en los diversos campos de la investigación, la literatura y el pensamiento»(1998: 34). De hecho, en el texto introductorio al «Plan general» que cita Nigel Dennis, se observa el carácter inclusivo que Bergamín otorga a la noción de «pensamiento en lengua española»: pensadores, poetas, investigadores $\mathrm{y}$ artistas, todos, de todo tiempo, por tradición y por novedad, contribuyeron generosamente a dibujar «la fisionomía propia cultural de España», que es, ante todo, «espiritual» (Dennis, 2005: 30) -como anticipando la noción, ahora difundida a nivel mundial, como lo es la de «Patrimonio inmaterial de la humanidad» de la UNESCO.

Conocido y a menudo criticado es el anclaje político de Séneca, cuya lealtad para con la Segunda República indicaban sin duda las iniciales de las cuatro colecciones que la componían: LEAL (Laberinto, Estela, Árbol, Lucero). El vínculo establecido en el exilio por los intelectuales entre la idea de una cultura española universal y la Segunda República, también universal por los ideales políticos que cristalizaba (la democracia y la libertad) no se puede entender si no se toma en cuenta que, desde atrás, en Madrid, Bergamín había escogido para Las ediciones del árbol, el emblema del hortus philosophae. Al contrario de lo que se ha podido afirmar, Bergamín era ante todo un hombre de letras, no un hombre político. Además del aspecto simbólico, espiritual y metafísico del emblema, cabe recordar, según la frase de Nigel Dennis, que con aquel "gesto audaz», Bergamín establecía un vínculo entrañable con la Segunda República, y las promesas que se abrían entonces para España (1986: 156).

Importa, pues, insistir en que durante el primer período del exilio y en una época que ha sido caracterizada como ideológica, hispanismo y universalismo se complementaban para sostener una concepción no ideológica del saber, cristalizada en la Segunda República española. En los siguientes apartados, basándome en la terminología de Pierre Bayard, mostraré que la primera época del exilio republicano español (1939-1945) es reveladora de la «biblioteca interior» que llevaban los intelectuales de la primera generación. Tomaré como figuras centrales a dos grandes «lectores» (siguiendo la terminología de 
Bayard, 2007): José Bergamín y Juan David García Bacca, por su protagonismo en la Editorial Séneca, ya sea como director editorial o como autor.

\section{La «biblioteca real» del exilio en las trayectorias de José Bergamín y Juan David García Bacca}

Es imposible proponer aquí un catálogo exhaustivo de los volúmenes que llevaron consigo los exiliados españoles a las tierras americanas; menos aún, los que pudieron haber llevado. Ello supondría, consultar las bibliotecas individuales de dichas personalidades ${ }^{11}$; comparar los fondos correspondientes hasta el límite del período estudiado; emitir una hipótesis sobre los libros no poseídos por los protagonistas que no obstante circularon entre bibliotecas reales, etc. Dados los límites de este trabajo, me pareció sugerente examinar las trayectorias de José Bergamín y Juan David García Bacca, hasta su marcha a Caracas en 1946.

Si comparo la trayectoria vital e intelectual de ambos en los años 1920 y 1930, poco parecen compartir, a primera vista, el polifacético intelectual, esqueleto «fantasmal» y poeta "crucificado», peregrino en su patria que fue el doblemente exiliado Bergamín y el amado profesor de filosofía e ilustre filósofo, musicólogo y poeta, «español de las Indias», García Bacca. Bergamín solía describirse como un autodidacta ante todo; de conservador en su juventud, pasó a ser una de las voces más singulares del catolicismo europeo de preguerra. García Bacca tuvo formación neoescolástica religiosa en España, que completó en los años treinta en centros importantes universitarios en Europa, inclinado por el desarrolló de su pensamiento original en física y matemáticas, que daría origen a varias de sus obras, reconocidas mundialmente. Doctor en Filosofía por la Universidad de Barcelona, nunca pudo ocupar la cátedra en la Universidad de Santiago que había ganado por oposición en Madrid en 1936, al estallar la guerra. Ambos combatieron en su vida y en sus escritos todas las formas del saber dogmático e institucionalizado, con gracia «taurina» (García Bacca, 2000; Foehn, 2011).

Como ya señalé, la biblioteca de Bergamín fue destruida por las tropas franquistas cuando él se encontraba en Estados Unidos como delegado oficial de la República; en 1938, García Bacca llegaría a Quito, donde se radicaría hasta 1942, con nada más que un smoking comprado en París y un par de cajas de libros rescatados de su biblioteca en la Universidad de Barcelona (García Bacca, 70; García Palacios, 50). En varias ocasiones declaró Bergamín que las influencias decisivas de su juventud no eran españolas, sino alemanas, italianas y francesas, en orden creciente de preponderancia. En palabras de Nigel Dennis, sus vastos conocimientos de la literatura española, especialmente la del Siglo de Oro, los «adquiriría posteriormente», a finales de los años veinte (2005: 11). Comentó el mismo que «empiez[a] a leer a Cervantes en serio a los 40» (Bergamín \& Sánchez Erauskin, 1995: 226), lo que nos llevaría a 1935. El dato no es casual, dada la trascendencia que tomaría la figura de Don Quijote en el exilio (Abellán, 2003; Aznar Soler, 2005; Mainer, 2006; Peyrebonne, 2008).

En cuanto a las lecturas españolas de García Bacca, resulta difícil atar cabos hasta su salida al exilio. En Confesiones, redactado un año antes de su muerte en 1991, menciona como lectura obligatoria La perfecta casada de Fray Luis de León. No es casualidad, sin embargo, que utilice como edición de referencia de El ingenioso hidalgo Don Quijote de la Mancha, precisamente la de Séneca, de 1941, para Sobre El Quijote y Don Quijote de la 
Mancha, publicado en 1991, en vez de la más reciente. Tampoco es casualidad que, de igual modo, se refiera en una de sus obras más importantes, Invitación a filosofar según espíritu y letra de Antonio Machado, a la edición en Séneca de las Obras completas de Antonio Machado, de 1940. En mi opinión, es una manera a la vez discreta y resuelta de reafirmar a lo largo de su vida su pertenencia a la «España Peregrina» de Bergamín (García Bacca en Ángel Nogueira, 1991: 152).

Entre las lecturas que irán conformando la biblioteca interior de los escritores republicanos en exilio, destaca la figura de Antonio Machado, cuyas Obras completas abrirán el catálogo de la colección «Laberinto» de la Editorial Séneca y que Bergamín presentaba así:

Este volumen, el primero de la "Colección Laberinto» publicado por la Editorial Séneca bajo la dirección de José Bergamín y al cuidado tipográfico del poeta Emilio Prados. Se terminó de imprimir el día dieciseis de octubre de mil novecientos cuarenta, en los Talleres Gráficos Cultura de la Ciudad de México. Única edición autorizada para los países de lengua española. Queda hecho el depósito de la marca de ley ${ }^{12}$.

\section{Antonio Machado en la Editorial Séneca}

21 Es central la obra de Antonio Machado en la biblioteca interior de los escritores en el exilio porque, en gran medida, les sirve para conectarlos con el pasado del populismo republicano. Gonzalo Santonja describe perfectamente la recuperación y censura que hizo el régimen franquista de la obra del poeta muerto en el exilio, mediante la edición en Espasa-Calpe de su Poesía completa, al «cuidado» de Dionisio Ridruejo:

Antonio Machado, enemigo convicto por republicano confeso, fue algo así como perdonado post-mortem, [...]: trastocado de enemigo en amigo y de ajeno en nuestro, en prodigiosa manifestación del arte del escamoteo y la proverbial facundia del Nuevo Régimen, que adornó su Victoria, a juzgar por las trazas, con la autoconcesión de la falcutad alquimista del invento y la reinterpretación (1997: 103).

No es mi propósito repetir la acertada, irónica e indignada crítica de Santonja a la edición de Ridruejo de la obra poética de Machado. En cambio, es de primordial importancia para entender el puesto otorgado al pensamiento de Machado por los intelectuales del exilio y, en particular, por Bergamín desde los años de guerra y García Bacca a partir de los años sesenta ${ }^{13}$, lo que Santonja evidencia plenamente a continuación: la censura de la obra de Machado prosista, el de Juan de Mairena (1997: 106-107). De hecho, Santonja muestra que Ridruejo desacreditó a Machado como pensador:

Juan de Mairena: se mentó la cuerda en la casa del ahorcado. Remediable con azul voluntad el asunto de las poesías, éste de las prosas carecía de remedio. Se imponía, pues, «frivolizar» los «análisis» y cerrarlos con el atrevido corolario de una cadavérica seudobroma: la de atribuir a la censura el benefactor propósito de aliviar al autor y favorecerle. Insustancial, tontorrona y prescindible aquella parte de su obra, se tachaba y en paz. ¿Antonio Machado prosista? ¡Por Dios! ¿Antonio Machado hombre de ideas? Qué cosas, valiente exageración. Poeta grande de la España eterna, lo que procedía en proclamarle gran cantor nuestro.

La edición de Séneca de las Obras completas de Antonio Machado constituye, pues, el «contrapunto» a la de Escasa-Calpe, reconocida de manera unánime por la crítica como «modélica», «poco menos que milagrosa», para las circunstancias - problemas prácticos, de orden económico, o la imposibilidad de tener todo el material necesario para una 
edición definitiva- (Santonja, 1997: 119; Pastor Pérez, 2006; Dennis, 1995). Como he señalado, ni Bergamín ni García Bacca escamotearon la dimensión filosófica de la obra machadiana, sobre todo la del Cancionero apócrifo. Al contrario, la iluminan y la celebran, hasta convertirla García Bacca en fundación de su propio filosofar. Analizaré a continuación el Prólogo de Bergamín de 1940 a las Obras completas de Antonio Machado y el Prólogo de Juan David García Bacca a su Invitación a filosofar según espíritu y letra de Antonio Machado, con el fin de mostrar cómo ambos, mediante la figura del «filósofo del pueblo» o callejero, tan difundida en los escritos de los pensadores de su generación, entendían el filosofar como un «acto de democracia ${ }^{14} »$.

\section{José Bergamín prologuista de las Obras completas de Antonio Machado en la Editorial Séneca}

El aprecio de Bergamín por Machado remonta a la época de Cruz y Raya, más precisamente a la época que precede su creación. Reconocía en él a un «maestro» ${ }^{15}$, como, por confesión propia, consideraba a Ortega, Unamuno y Falla. A través de tales «maestros», Bergamín «ha intentado expresar no solamente la reverencia personal que sentía por esas figuras, sino también el sentido oculto, último de su pensamiento y labor creativo» (Dennis, 1998: 162). Después de recordar que Antonio Machado pensaba ofrecer su Juan de Mairena a las Ediciones del Árbol (cuando se publicaría finalmente en la Editorial Séneca), Dennis añade que fue durante la guerra civil cuando «la amistad y mutua admiración que unían a estos dos escritores cuajaron de verdad» (1998: 163). Considera a continuación que Machado fue «uno de los lectores más atentos de la obra de Bergamín y lamenta que no tuviera tiempo para volver a escribir sobre ella» (1998: 164). Bergamín dedicó varios ensayos a Machado: todos, afirma Dennis, «descubren cómo estimaba el ejemplo de este escritor humilde y tímido detrás de cuya voz resonaba la indignación del pueblo español» (1998: 165). Es aquella timidez un motivo que, precisamente, recuperaría Juan David García Bacca en Invitación a filosofar según espíritu y letra de Antonio Machado.

Como trasfondo implícito o «invisible» del pensamiento bergaminiano corre el conocido refrán popular, «vox populi, vox Dei», cristalizado en el Prólogo a las Obras completas que comento a continuación. La identificación que establece Bergamín entre el poeta y el pueblo se hace posible mediante la dialéctica del ensimismamiento y del enfurecimiento de la voz poética:

\section{ANTONIO MACHADO}

Cuando hablaba tenía un dejo de timidez y de altivez.

[...] Ningún hombre es visible, decía Lulio. Si no tiene un pueblo detrás, añadiríamos. Un hombre es visible cuando tiene un pueblo detrás. El pudor solitario de una voz de poeta, como de una voz de mujer, se viste visiblemente, de este modo, que diríamos sangriento, cuando un pueblo entero respalda esa voz viva. Y decimos sangriento porque es su mortal e inmortal empeño como el de la túnica de sangre en el mito helénico, como el de la púrpura ensangrentada en el Cristo vivo; vestidura, lenguaje trágico para quien lo dice. Ante la muerte, el testimonio de la sangre efusiva vela púdicamente la voz desentrañada de su ser y hace visible para todos el pensamiento que tales palabras verdaderas expresan.

Yo he visto subir al poeta, un claro mediodía, a un tingladillo levantado en medio de la plaza más grande de Valencia. Le rodeaba una inmensa muchedumbre. Parecía que subía al cadalso. Mas no ahogaba su voz; por el contrario, habló, desde allá, arriba con tal fuerza que aquel dejo tímido y altivo de su palabra la iba desnudando o, mejor digo, vistiéndola de sangre, por un pensamiento que expresaba los sentimientos en conmoción de todos los pueblos de España. 
Cantaba el poeta la muerte de Federico García Lorca. Y quienes escuchábamos aquella voz, tímida y altiva voz que tantas veces escuchamos al cobijo de su intimidad solitaria, la veíamos, por primera vez, dibujando en los aires su contorno con precisión exacta, con veracidad justa. No hablaba el poeta para nosotros, hablaba por nosotros (Bergamín, 1984: 84). aquella timidez no es tan sólo un rasgo de carácter, sino que corresponde al ethos, por así decirlo, del poeta por antonomasia. El riesgo que corre el poeta al dar en público su voz es traicionar la verdad de su ser más íntimo y profundo, al que Bergamín llama «hombre invisible» ${ }^{16}$. En el primer párrafo, Bergamín establece primordialmente el vínculo entre el poeta y el pueblo. Afirma explícitamente que «un hombre es visible cuando tiene un pueblo detrás», «cuando el pueblo respalda esa voz viva [del poeta]». No por demagogo o por ansias de popularidad se acerca el poeta al pueblo sino por las circunstancias «sangrientas» que los une; o, dicho de otro modo: sólo trágicamente es el poeta popular. El segundo párrafo anuncia el tema del mediodía, que será explicitado más adelante como el momento de máxima lucidez, como la hora de mayor claridad de conciencia que coincide necesariamente con la de la muerte, representada por la simbólica subida al cadalso: suerte compartida tanto por el poeta como por el pueblo que le respalda ${ }^{17}$. Condena a muerte que fue la del poeta cantado por Machado, Federico García Lorca.

Anfurecerse, es decir, al volverse testigo de la «sangre efusiva» que tan generosamente daba el pueblo español a Europa por la democracia y la libertad, la voz del poeta, antes ensimismada, en adelante «expresaba los sentimientos en conmoción de todos los pueblos de España». Voz testimonial que será en adelante también la de Bergamín, lo que bien entendió Jean Cassou en la carta fraternal que le dirigió en $1941^{18}$.

La marca de la guerra civil y del exilio es aún plenamente visible en el Prólogo que escribe Bergamín a las Obras completas de Antonio Machado en la Editorial Séneca. En cierta medida, el volumen constituye a la vez un homenaje a la generación literaria anterior y la afirmación de la suya como depositaria de la memoria de la España dejada atrás. Otra será la aproximación que tomará García Bacca al publicar Invitación a filosofar según espíritu y letra de Antonio Machado en 1967: inactual.

\section{Juan David García Bacca en la Editorial Séneca: tres estudios de caso («libro fantasma», «libro pantalla» $y$ «libro real»)}

García Bacca adopta una aproximación inactual al pensamiento poético de Antonio Machado. La inactualidad del pensamiento filosófico es reivindicación antigua por parte de los filósofos y no constituye en sí una originalidad propia del autor. De hecho, en el Prólogo a Invitación a filosofar según espíritu y letra de Antonio Machado, no deja trasparentar el recuerdo de la guerra civil ni el del exilio, como tampoco evoca la agitada actualidad de sus tierras americanas de adopción. Por lo tanto, sería, sin duda, admisible argumentar que se refiere a la edición de Séneca por razones meramente circunstanciales y prácticas (es decir, no tener otra más reciente y actualizada a mano). En mi opinión, como ya he señalado, García Bacca reafirma su compromiso para con la Segunda República -es decir, con la democracia - y con el legado espiritual de la España peregrina.

Las contribuciones de García Bacca en Séneca suman tres: dos traducciones y una aportación original. En «Árbol», García Bacca publicó Filosofía de las ciencias. Teoría de la relatividad en 1941, una revisión y ampliación de su tesis doctoral; en 1944, como

ILCEA, 25 | 2016 
traductor de Heidegger, Hölderling [sic] y la esencia de la poesía. En «El Clavo Ardiendo» tradujo Presencia y experiencia de Dios, de Plotino, en 1942. De por sí, los títulos bastan para indicar la amplitud de los conocimientos de García Bacca en campos especializados del saber a priori poco comunicados entre sí: la física contemporánea, la filosofía neoplatónica-mística y el existencialismo de Heidegger -en especial, sus reflexiones en torno a la poesía. Como muchos de los volúmenes publicados por Séneca, son libros poco asequibles hoy; sólo Hölderlin y la esencia de la poesía fue editado en versión revisada en Caracas en 1968. Forman parte, no obstante, de la «biblioteca colectiva» del exilio republicano español y, en los años 1940, eran elementos imprescindibles, a mi entender, de lo que llamé la «sinfilosofía» del exilio -o filosofar colectivo y poético del exilio republicano español en México- (Fœhn, 2011). A continuación y retomando las categorías definidas por Pierre Bayard (2007), mostraré cómo las tres obras citadas representan respectivamente, a mi modo de ver, un «libro fantasma», un «libro pantalla», $\mathrm{y}$, por último, un «libro real».

31 Presencia y experiencia de Dios correspondría a la primera categoría. Hoy día, libro «fantasma» en sentido casi literal de la palabra: no se encuentra ejemplar en Europa (sí en la Biblioteca Nacional de México). En cambio, la investigación documenta que formó efectivamente parte de las bibliotecas personales de Emilio Prados (Chica, 1999: 188) y María Zambrano ${ }^{19}$ - cuya concepción del ser está, en parte, basada en la mística plotiniana.

Filosofía de las ciencias. Teoría de la relatividad correspondría a la segunda categoría. El volumen se presenta como una antología de los escritos de los principales físicos de la relatividad, como Einstein y Minkowski. Menciono este último porque Bergamín filósofo no convencional y antiacadémico si lo hay- lo cita nominalmente en su importante ensayo de 1957, Fronteras infernales de la poesía. De la introducción de esta obra extraje una cita que aún me parece sugerente: «la física moderna no es "ciencia natural", es arte». Pese a que García Bacca no dedicara ningún trabajo a la estética -aunque esta estuviera presente en muchos escritos suyos- revela la vertiente científica, complementaria de la literaria y poco estudiada por los investigadores, de la «razón poética» que iban inventando los intelectuales republicanos españoles en el exilio.

Hölderling [sic] y la esencia de la poesía correspondría a la tercera categoría. Refiriéndose a la traducción publicada en 1944 en Séneca, en el prólogo a la traducción revisada de 1968 que preparaba y publicó en Caracas (la cual se reeditó posteriormente en 1989 en la editorial barcelonesa Anthropos), García Bacca escribió, probablemente con razón: «me complazco en pensar que fue la primera traducción al castellano». Según confesión de García Bacca, al poco tiempo de llegar a las estanterías de las librerías en la capital mexicana, se retiraron los ejemplares de la venta casi en seguida, por intervención de Alfonso Reyes (García Bacca, 2000: 83-84).

Volvamos, pues, a Invitación a filosofar según espíritu y letra de Antonio Machado, única obra de García Bacca traducida al francés. En una nota a la traducción que refleja cierta perplejidad, el editor, Michel Valensi, escribió, jugando con los dos sentidos de la palabra «datée», que significa en francés a la vez fechada y obsoleta:

Cette préface est «datée »: 26 juin 1965. En 1992, nous avions écrit à l'auteur pour lui demander s'il souhaitait la maintenir sous cette forme ou lui apporter quelque mise à jour qui, selon nous alors, s'imposait, ou plutôt lui était imposée par, disons, le "tour » qu'avait pu prendre, ou le tour que nous avait joué les choses, concernant la démocratie, le peuple, etc. - autant de concepts qui depuis 1965 ont, c'est le moins qu'on puisse dire, subi les assauts de l'histoire. García Bacca est mort en août 1992, sans pouvoir répondre à notre 
lettre, et nous avons songé un temps, soit supprimer cette préface (en signalant, bien entendu, cette suppression) soit la "passer » en postface, comme sont " passés en postface ", le peuple et la démocratie au nom du Peuple et de la Démocratie. Elle "ouvre» finalement cette édition française, comme celles précédentes en espagnol, en mémoire d'un homme qui désormais "suit des yeux dans l'aquarium profond, les possons non plus vifs mais fugitifs (que nous sommes)", mais aussi parce qu'à la réflexion il se peut que ce soit nous qui, aujourd'hui, portions notre "date», et non point tant ces paroles simples, "filles du long désir ». (García Bacca, 1994: 8)

Para terminar, intentaré explicar brevemente, por qué me parecen imprescindibles estas «palabras iniciales», comparando el prólogo de Valensi con el de Bergamín, ya estudiado. El prefacio a Invitación a filosofar según espíritu y letra de Antonio Machado se abre con una cita larga de Juan de Mairena en que el filósofo apócrifo reconoce en el pueblo a su maestro, al igual que García Bacca. Cito el fragmento final:

También el autor querría escribir para el Pueblo -para nuestros pueblos hispanoamericanos: sobre sus problemas seculares no resueltos por las secularmente llamadas soluciones, y escribir sobre sus nuevos problemas a cuya solución no sólo no van a servir de nada las viejas, sino, de servir, lo serán de obstáculos.

Aunque los temas y su desarrollo parezcan dirigidos a una clase distinguida, apelan a los que, filósofos o no, tengan todos de pueblo, que aquí, en Hispanoamérica, es casi todo - por todo.

El autor mismo ha tenido que hacer un esfuerzo para descender a su estrato popular -de abuelos labradores; de padres, sencillos maestros de escuela. Esta obra es, pues, un acto de democracia (García Bacca, 1984: 8).

A diferencia de Bergamín, García Bacca no evoca, directa o indirectamente, la guerra civil española, ni su compromiso con la Segunda República que le forzó al exilio. De hecho, apenas trasparece en su propósito el agitado contexto político de América Latina de finales de los años sesenta, por no hablar de España. Al «Pueblo» se le puede fácilmente oponer la categoría de "Tirano», encarnado, en el contexto contemporáneo, en los dictadores y juntas militares que usurparon el poder en ambas orillas del Atlántico. Si el filósofo quiere escribir para el «Pueblo» (o comunidad de pueblos de habla española, como bien indica) -no para demás filósofos- es para proporcionarle los instrumentos conceptuales y críticos que le permitan restablecer la democracia, y recobrar su libertad, no dictarle un modo de pensar.

\section{Conclusión}

37 La «biblioteca interior», desde luego, se compone de libros «reales» que, como he mostrado en el caso de los tres volúmenes publicados por García Bacca en Séneca, pueden pasar de una categoría «bayardiana» de libro a otra, e incluso superponerse, según la situación histórica -o incluso geográfica- en que se encuentre. Esa relatividad categorial es inherente a la condición exílica, la cual afecta aún la producción cultural de la España del exilio, repatriada sólo en parte. Por otra parte, a través de la figura de Antonio Machado, he intentado «rescatar» una parte, a la vez ínfima y ejemplar de la «biblioteca interior» del exilio republicano, que es constituyente del diálogo que se entabla entre filósofos y poetas. Pensemos en las reuniones en la sede de la Editorial Séneca transcritas en El Hijo Pródigo, o en Retablo hispánico, obsequio diplomático dirigido por el gobierno republicano en el exilio al gobierno mexicano (Palenzuela, 2001). 
Un libro es un objeto que nos viene de lejos», nos dicen los filósofos Chris Younès y Benoît Goetz. «Es testimonio de un mundo no enteramente perdido». Con ese trabajo sobre algunos libros a la par fantasmales y reales publicados en la Editorial Séneca, espero haber revivificado parte del mundo no enteramente perdido de la España peregrina.

\section{BIBLIOGRAFÍA}

ABELLÁN José Luis (1999), «España peregrina y el significado del transtierro», X. L. Axeitos Agrelo \& M. del R. Portela Yáñez (eds), Sesenta anos despois. Os escritores do exilio republicano: actas do Congreso Internacional celebrado na Universidade de Santiago de Compostela (117-124).

ABELLÁN José Luis (2003), «Don Quijote como símbolo del exilio», M. Lluisia \& A. Alted Vigil, La cultura del exilio republicano español de 1939. Actas del Congreso plural: Sesenta años después (545-554), Madrid: UNED.

ARMENDÁRIz SÁNCHEZ Saúl \& ORDoÑEZ ALONSO María Magdalena (1999), «La aportación de los refugiados españoles a la Bibliotecología Mexicana: nota para su estudio», Clio. History and History Teaching, 8, <http://clio.rediris.es/clionet/articulos/exiliados.htm> (consultado el 22/11/2015).

ASCUNCE ARRIETA José Ángel (1989), «Redescubrimiento de América por la España peregrina», M. Criado de Val (dir.), Literatura hispánica, Reyes Católicos y descubrimiento: actas del Congreso internacional sobre literatura hispánica en la época de los Reyes Católicos y el descubrimiento (569-578), Barcelona: Diputación Provincial / Promociones Publicaciones Universitarias de Barcelona.

AZNAR SOLER Manuel (2005), «Don Quijote y el exilio republicano español de 1939», Laberintos. Revista de estudios sobre los exilios culturales españoles, 5, 93-136.

AZNAR SOLER Manuel (2007), Valencia, capital literaria y cultural de la República (1936-1937), Valencia: Publicaciones de la Universidad de Valencia.

BAYARD Pierre (2007), Comment parler des livres que l'on n'a pas lus?, París: Les Éditions de Minuit. Bergamín José (1985), Prólogos epilogales, Valencia: Editorial Pre-textos.

BERGAMín José \& SÁNCHEZ ERAUSKIN Javier (1995), Escritos en Euskal Herria, Tafalla: Editorial Txalaparta.

CHICA Francisco (1999), El poeta lector. La biblioteca de Emilio Prados, The Barracks: La Sirena.

DE LOURDES PASTOR María (2006), «La edición de las Obras de Antonio Machado en Editorial Séneca (México, 1940)», M. Aznar Soler, Escritores, editoriales y revistas del exilio (565-572), Sevilla: Renacimiento.

DenNis Nigel (1999), «Emilio Prados en la Editorial Séneca», Revista de Occidente, 222, 109-121.

DENNIS Nigel (1986), José Bergamín. A Critical Introduction (1920-1938), Toronto-Buffalo-London: University of Toronto Press.

DENNIS Nigel (1995a), «Cultura y exilio: Bergamín y la primera edición de las Obras completas de Antonio Machado», Revista de Occidente, 166, 100-112. 
DENNIS Nigel (1995b), «Ensimismamiento y enfurecimiento en la poesía de José Bergamín (1939-1946)», R. Corral, A. Souto Alabarce \& J. Valender (eds), Poesía y exilio: los poetas del exilio español en México (221-230), México: El Colegio de México.

DenNis Nigel (2005), «Prólogo», J. Bergamín, El pasajero. Peregrino español en América (México, 1943-1944) (7-48), A Coruña: Castro.

DíAz ARciniega Víctor (2014), «Séneca. Una casa para la resistencia», Trama \& Texturas, 24, 109-130.

EISENBERG Daniel (1985), «Las publicaciones de la Editorial Séneca», Revista de literatura, 47(94), 267-276.

FÉRRIZ ROURE Teresa (2002), Estudio de España Peregrina: una revista para la continuación de la cultura española en el exilio mexicano, Alicante: Biblioteca Virtual Miguel de Cervantes. Edición parcial de la tesis doctoral Revistas literarias del exilio español de 1939 en México: estudio de España peregrina (1940) y Romance (1940-1941), Universitat de Lleida, 1994, <www.cervantesvirtual.com/nd/ark:/59851/ bmc28076> (consultado el 22/11/2015).

FoEHN Salomé (2011a), «De la raison ludique à la raison poétique. José Bergamín, philosophe taurin», C. Fillière \& L.-A. Laget (coord.), Les relations esthétiques entre ironie et humour en Espagne (184-200), Madrid: Casa de Velázquez.

FoEHN Salomé (2011b), Les philosophes de l'exil républicain espagnol de 1939. Autour de José Bergamín, Juan David García Bacca et María Zambrano, Tesis doctoral, Université Paris 3 Sorbonne NouvelleUniversity of St-Andrews.

FoEHN Salomé (2014), «Habiter l'exil : Retablo hispánico, Mexique, 1946», Cahiers de civilisation espagnole contemporaine, 12, <http://ccec.revues.org/5060> (consultado el 22/11/2015).

GARCíA BACCA Juan David (1941), Filosofía de las Ciencias. Teoría de la Relatividad, México: Editorial Séneca.

GARCíA BACCA Juan David (1984), Invitación a filosofar según espíritu y letra de Antonio Machado, Barcelona: Anthropos.

GARCíA BACCA Juan David (1994), Invitation à philosopher selon l'esprit et la lettre d'Antonio Machado, Combas: Éditions de l'Éclat.

García BACcA Juan David (2000), Confesiones, Barcelona: Anthropos.

GARCía PALACIOS Francisco (2003), «Semblanza humana de Juan David García Bacca», El pensamiento de Juan David García Bacca, una filosofía para nuestro tiempo: actas del Congreso internacional de Filosofía (47-58), Deusto: Universidad de Deusto.

GonZÁLEZ CASANOVA José Antonio (1995), Bergamín a vista de pájaro, Madrid: Turner.

HEIDEGGER Martín (1944), Hölderling y la esencia de la poesía, trad. por J. D. García Bacca, México: Editorial Séneca.

HidAlgo NÁCHER Max (2014), «De una España peregrina a una España fantasmal: las imposibles vueltas de José Bergamín», M. Aznar Soler, J. R. López García, F. Montiel Rayo \& J. Rodríguez (coord.), El exilio republicano de 1939: viajes y retornos (626-637), Sevilla: Renacimiento.

MAINER José-Carlos (2006), Moradores de sansueña (lecturas cervantinas de los exiliados republicanos de 1939), Valladolid: Universidad de Valladolid.

NogueIRA Ángel (coord.) (1991), «Juan David García Bacca. La filosofía, una empresa de creación del pensamiento», número monográfico de Anthropos, 9. 
PASTOR PÉREz María Lourdes de (2006), «La edición de las Obras completas de Antonio Machado en Editorial Séneca», M. Aznar Soler, Escritores, editoriales y revistas del exilio (565-572), Sevilla: Renacimiento.

PALENZUela Nilo (2001), El hijo pródigo y los exiliados españoles, Madrid: Verbum.

PeyrebonNe Nathalie (2008), «Résistances quichottesques aux $\mathrm{Xx}^{\mathrm{e}}$ et $\mathrm{xxI} \mathrm{e}^{\mathrm{e}}$ siècles», Pandora : revue d'études hispaniques, 8, 19-36.

SÁNCHEZ Cuervo Antolín, NAVARRo López Vicente \& ABAD NeBot Francisco (coord.) (2008), Las huellas del exilio. Expresiones culturales de la España peregrina, Madrid: Editorial Tébar.

SANTONJA Gonzalo (1997), Al otro lado del mar. Bergamín y la Editorial Séneca (México 1939-1949), Barcelona: Galaxia Gutenberg.

PAQUOT Thierry \& YOUNÈs Chris (dir.) (2009), Le territoire des philosophes. Lieu et espace dans la pensée au $\mathrm{XX}^{e}$ siècle, París: La Découverte.

\section{NOTAS}

1. En cuanto al nombre de la Editorial y a la decisión de Bergamín de bautizarla con el nombre del ilustre filósofo romano, Nigel Dennis (2005: 30-31) apunta lo siguiente: «La editorial es bautizada con el nombre de Séneca, filósofo español por excelencia para Bergamín. Además, se trata de una figura de la literatura clásica que padeció el exilio en diversas etapas de su vida y escribió páginas admirables sobre el tema. Por otra parte, no hay que descartar la colaboración de Gallegos Rocafull, gran conocedor de la obra de Séneca, a la hora de elegir el nombre de la editorial. Sin embargo, más allá de estas explícitas resonancias senequistas, el espíritu combativo de la empresa, se resume major, a mi modo de ver, en el logotipo utiliado por la colección Lucero: el ave fénix, que renace de las llamas de la hoguera, reafirmando así el impulso creador y desfiante que caracteriza el plan de actividades que se pretende llevar a cabo». Por mi parte, apunté en mi tesis doctoral la resonancia que sintieron los intelectuales republicanos españoles entre su condición de redescubridores de América y la profecía del descubrimiento de América que supuestamente hizo Séneca en su tragedia Medea. A ese paralelismo se alude en el primer número de la revista España Peregrina (2011: 287 y siguientes).

2. La Editorial Séneca existió entre 1939 y 1949, aunque su período de plena actividad corresponde a la estancia en México de su Director literario, artístico y técnico, José Bergamín (Dennis, 2005: 34). Al igual que Juan David García Bacca, se marchó a Caracas en 1946. De ahí las fechas consideradas en el presente estudio.

3. De aquellos encuentros que tuvieron lugar entre los filósofos y hombres de letras más señalados del exilio republicano español y de la intelectualidad mexicana en los locales de Séneca dejó constancia la revista El Hijo Pródigo (Palenzuela, 2001).

4. Fragmento de una carta que me dirigió Nigel Dennis el 4 de diciembre del 2008. Traduzco del original en inglés: «When I was in San Sebastian recently I met a man whose name was vaguely familiar (he had edited a book by Luisa Carnés for the Biblioteca del Exilio). We had a cup of coffee together one day and the subject of the Junta de Cultura came up. He said he had visited the archives of the Ministerio de Asuntos Exteriores some years ago and found a document concerning the creation of the Junta. I asked for a copy and he sent it to me. It turns out to be the proposal Bergamín submitted to Juan Negrín in early 1939 for the foundation of the Junta, giving all the reasons (not mentioned later in the official documents on the subject) why the Junta was necessary at the time. In other words: a priceless, historic document, directly concerned with an issue I'm keenly interested in.» 
5. La Biblioteca del Exilio es, en palabras del Comité Editorial, «una colección que, nacida en el año 2000, propone publicar al menos cien obras de autores de nuestro exilio republicano de 1939, escritas en cualquier lengua de nuestra República literaria». Es responsabilidad del Grupo de Estudios del Exilio Literario (GEXEL) de la Universitat Autònoma de Barcelona (UAB).

6. Por definición, es el que no lee libros. De manera más específica, es quien habla de los libros que no ha leído, es decir, según P. Bayard, el hombre educado, de cultura, cuya búsqueda consiste en alcanzar la totalidad (2007:25). Los libros no leídos pueden causar efectos sensibles en nosotros por los ecos que nos llegan de ellos (2007: 16). Dado que la búsqueda de la totalidad es la finalidad de la verdadera cultura, prevalece la necesidad de relacionar los libros entre sí, sobre la obligación de leer un libro solo. Por lo tanto, la cultura es ante toda una cuestión de orientación, personal y, desde luego, colectiva.

7. Se define como el dominio de las relaciones entre los libros (Bayard, 2007: 28). Los «libros colectivos» resultan de los intercambios que sobre los libros reales se realizan entre no-lectores. Asimismo es el espacio que, según P. Bayard, todos habitamos; el espacio mediante el cual organizamos el saber de manera totalizadora. Aquel espacio organizado, sin embargo, se encuentra potencialmente amenazado por cualquier libro individual capaz de desorganizarlo, al que, por lo tanto, se excluye del conjunto.

8. La biblioteca interior, según P. Bayard, es el conjunto de libros a partir del cual una personalidad se construye y la que luego organiza su relación a los textos y a los demás. El libro interior es la imagen ideal de un libro perfecto; puede ser colectivo e individual a la par (caso del tomo perdido de la Poética de Aristóteles en El nombre de la rosa, de Umberto Eco).

9. Aunque, como indica Nigel Dennis, esta última no dependiera directamente de la Junta (2005: 28).

10. Sobre la discrepancia entre el proyecto y su realización, véase también, entre otros, Díaz Arciniega (2014: 127).

11. En 2011, se ha repatriado, desde Quito, la biblioteca personal de Juan David García Bacca en la Biblioteca de Navarra en Pamplona, ciudad natal del filósofo. Agradezco a Ángel García Larraz, sobrino del filósofo y representante de la Fundación Juan David García Bacca, con sede en Caracas y a Juan Francisco Elizari, Director de la Biblioteca de Navarra, su ayuda preciosa durante mi primera estancia en Pamplona en julio del 2014.

12. No me ha sido posible consultar la edición de las Obras completas de Antonio Machado en la Editorial Séneca. Agradezco al Dr. Eduardo Pólit Molestina, Director de la Fundación Juan David García Bacca, la sugerencia de incluir este texto original de Bergamín que sirvió para presentar la nueva colección con ocasión de la publicación de las Obras completas de Antonio Machado.

13. Cristina de la Cruz, en el trabajo que dedica a la presencia de Antonio Machado en García Bacca, no repara en que Bergamín, como Director de la Editorial Séneca, fue probablemente el intermediario más obvio entre el poeta muerto en el exilio y el filósofo hispano-americano.

14. La expresión es de Juan David García Bacca.

15. Sigo a Nigel Dennis en el uso de las comillas, quien advierte contra la utilización de ese término, por resultar molesto a Bergamín (1998: 162).

16. No hay que olvidar que el subtítulo de El pozo de la angustia, también publicado en la Editorial Séneca, es «Burla y pasión del hombre invisible». Sin la clave del peculiar catolicismo de Bergamín, no se entiende el desenvolvimiento «dialéctico» del argumento en torno al hombre invisible y visible, encarnada por el poeta y el pueblo.

17. «Moría don Antonio cuando daba el reloj las doce...» (Bergamín, 1998: 86).

18. Esta carta fue publicada en 1941 en una separata que acompañaba los tres volúmenes de Bergamín reeditados en Séneca, Disparadero español III, Detrás de la cruz y El Pozo de la angustia. Véase la traducción al francés del Pozo de la angustia en Les éditions de l'Éclat, en la que va incluida. 
19. Se conserva hoy en los archivos de la Fundación María Zambrano (Vélez-Málaga). Sobre la relación documentada a partir de los archivos de la Fundación María Zambrano entre María Zambrano y Juan David García Bacca, véase mi tesis doctoral (2012: 346 y siguientes).

\section{RESÚMENES}

A principios de los años 1940 en México, la Segunda República española en el exilio otorgó fondos considerables para difundir la cultura española a nivel trasatlántico. Con ese fin fue creada en París en 1939, la Junta de Cultura Española (JCE) que se trasladó a México en 1940. Primero fundó España Peregrina, según la expresión acuñada por José Bergamín. También creó la Editorial Séneca. Ambas eran estrechamente relacionadas, dado que España Peregrina anunciaba las nuevas publicaciones de Séneca. Pero al contrario de España Peregrina, órgano de la JCE, Séneca gozaba de una gran autonomía en sus decisiones editoriales. Su «Plan general de publicaciones», ideado por José Bergamín, sigue tan celebrado hoy en día como criticado. Defendía una visión universalista de la cultura española. En este artículo, siguiendo a Pierre Bayard en Comment parler des livres que l'on n'a pas lus, propongo, primero, examinar Séneca en cuanto la «biblioteca interior» del exilio republicano español, para luego analizar el impacto de la edición en Séneca de las Obras completas de Antonio Machado en José Bergamín y Juan David García Bacca.

In exile, in the 1940s, the defeated Second Republic in Mexico bestowed considerable funds upon promoting Spanish culture. To this end, the Junta de Cultura Española (JCE) was created in Paris in 1939 and translated to Mexico in 1940. One of its first actions in exile was to create the journal España Peregrina, after José Bergamín's phrase. Another was to create the publishing house Séneca. Both were closely linked, as España Peregrina would regularly advertise Séneca's new publications. Unlike España Peregrina, the JCE's organ, Séneca was independent in its editorial choices. Its ambitious and still celebrated (as well as criticised) "General plan of publications" defended a universalist vision of Spanish culture. In this article, after Pierre Bayard's essay on libraries, I propose to consider Séneca as the "inner library" of Spanish Republican exile. I will first transpose Bayard's categories to the context of Spanish Republican exile and second, examine the impact of Séneca's edition of Antonio Machado's Complete Works on José Bergamín and Juan David García Bacca.

Au Mexique, dès le début des années 1940, la Seconde République espagnole en exil, consacra des sommes considérables pour perpétuer le rayonnement de la culture espagnole. À cette fin fut créée, à Paris, la Junta de Cultura Española (JCE) en 1939, pour s'établir à Mexico en 1940. L'une de ses premières actions en exil fut de fonder la revue España Peregrina, d'après la formule de Bergamín, parallèlement à la création de la maison d'édition Séneca. Toutes deux fonctionnaient en étroite collaboration, puis España Peregrina devait annoncer les nouvelles publications de Séneca. À la différence d'España Peregrina, qui était l'organe de la JCE, Séneca jouissait d'une grande autonomie dans la conception de son programme éditorial. Son «Plan général des publications ", pensé par Bergamín, est encore loué et critiqué aujourd'hui : il défendait une vision universaliste de la culture espagnole. Dans cet article, à la suite de Pierre Bayard dans son essai Comment parler des livres que l'on n'a pas lus, je propose, dans un premier temps, d'étudier Séneca comme la «bibliothèque intérieure » de l'exil républicain espagnole, pour analyser 
ensuite la marque durable de l'édition chez Séneca des Euvres complètes d'Antonio Machado sur José Bergamín et Juan David García Bacca.

ÍNDICE

Mots-clés: culture et Seconde République espagnole, exilés républicains au Mexique, Junta de Cultura Española, España Peregrina, Séneca, José Bergamín, Juan David García Bacca, Antonio Machado

Palabras claves: cultura y Segunda República española, exiliados republicanos en México, Junta de Cultura Española, España Peregrina, Séneca, estudios sobre el exilio, José Bergamín, Juan David García Bacca, Antonio Machado

Keywords: culture and the Second Spanish Republic in exile in Mexico, Junta de Cultura Española, España Peregrina, Séneca, exile studies, José Bergamín, Juan David García Bacca, Antonio Machado

\section{AUTOR}

\section{SALOMÉ FOEHN}

Université Sorbonne Nouvelle - Paris 3, CREC 